\title{
Application of Modified Electrocoagulation for Efficient Color Removal from Synthetic Methylene Blue Wastewater
}

\author{
Xiaoxue Duan ${ }^{1}$, Pan $\mathrm{Wu}^{1}$, Kewu Pi ${ }^{1,2, *}$, Huiqin Zhang ${ }^{1}$, Defu Liu ${ }^{1,2}$, Andrea R. Gerson ${ }^{3}$ \\ ${ }^{1}$ School of Resource and Environmental Engineering, Hubei University of Technology, Wuhan, Hubei \\ 430068, China \\ ${ }^{2}$ Hubei Key Laboratory of Ecological Restoration for River-Lakes and Algal Utilization, Wuhan, \\ Hubei, 430068, China \\ ${ }^{3}$ Blue Minerals Consultancy, Middleton, South Australia, 5213 \\ E-mail: pkw519@163.com
}

doi: $10.20964 / 2018.06 .15$

Received: 17 January 2018 / Accepted: 22 March 2018 / Published: 10 May 2018

\begin{abstract}
Treatment of synthetic wastewater containing methylene blue (MB) by electrocoagulation with periodic electrode reversal (PerevEC) was evaluated. The Response Surface Methodology (RSM) procedure was employed to obtain optimal conditions for decolorization, electrode consumption and sludge production which were found to be cell voltage of $3.1 \mathrm{~V}$, current density of $347 \mathrm{~mA} \cdot \mathrm{cm}^{-2}$, electrode reversal period of $2.5 \mathrm{~s}$ and inter-electrode gap of $2 \mathrm{~cm}$. Under these conditions $97 \pm 2 \%$ of the color was removed, the electrode consumption and sludge production were $0.25 \pm 0.02$ $\mathrm{kg}(\mathrm{Al}) \cdot \mathrm{kg}\left(\mathrm{MB}_{\mathrm{r}}\right)^{-1}\left(\right.$ where $\mathrm{kg}\left(\mathrm{MB}_{\mathrm{r}}\right)^{-1}$ is per $\mathrm{kg} \mathrm{MB}$ removed) and $1.9 \pm 0.9 \mathrm{~kg}$ (sludge $) \cdot \mathrm{kg}\left(\mathrm{MB}_{\mathrm{r}}\right)^{-1}$, respectively. NMR, IR and SEM analyses of the precipitates, solutions and electrodes for PerevEC and traditional electrocoagulation without periodic reversal of the electrodes (TradiEC) show greater $\mathrm{Al}_{13}$ Keggin ion polymer is formed in the electrolytic solution during PerevEC. Periodical reversal of the electrodes establishes improved conditions for precipitation and solution diffusion of $\mathrm{Al}^{3+}$ with decreased anodic passivation and cathodic polarization. For both PerevEC and TradiEC, the disappearance of characteristic IR peaks at 800-890, 1350, 1490 and $1604 \mathrm{~cm}^{-1}$ indicates the complete destruction of the methylene blue molecule by breakage of the central and side aromatic rings as well as demethylation. These results indicate that the PerevEC process, as compared to TradiEC, for dye wastewater treatment may be applied more widely due to the greater decolorization and reduced anodic passivation and cathodic polarization, although there is greater electrode consumption and sludge production.
\end{abstract}

Keywords: Electrochemical coagulation; Synthetic methylene blue wastewater; Periodical electrode reversal; Color removal, Response surface methodology

\section{$\underline{\text { FULL TEXT }}$}


(C) 2018 The Authors. Published by ESG (www.electrochemsci.org). This article is an open access article distributed under the terms and conditions of the Creative Commons Attribution license (http://creativecommons.org/licenses/by/4.0/). 